\title{
Bilateral acute retinal necrosis after herpetic meningitis
}

This article was published in the following Dove Press journal:

Clinical Ophthalmology

6 April 2012

Number of times this article has been viewed

\author{
Keisho Hirota ${ }^{1,2}$ \\ Masayuki Akimoto ${ }^{1,3}$ \\ Toshiaki Katsura ${ }^{2}$ \\ 'Department of Ophthalmology, \\ Kyoto Medical Center, National \\ Hospital Organization, ${ }^{2}$ Internal \\ Medicine, Kyoto Medical Center, \\ ${ }^{3}$ Clinical Research Center, Kyoto \\ Medical Center, Kyoto, Japan
}

Correspondence: Masayuki Akimoto Department of Ophthalmology, Osaka Red Cross Hospital, 5-30, Fudegasakicho, Tennojiku, Osaka, 543-8555, Japan

Tel +8I-6-6774-5I II

Fax +8I-6-6774-5|3|

Email masayuki@akimoto3.com
Purpose: The report of a case of bilateral acute retinal necrosis after herpetic meningitis. Case report: A 47-year-old man was admitted with the chief complaint of persistent high fever and transient loss of consciousness. Although his general condition improved after intravenous acyclovir administration, the patient presented with visual loss in both eyes 4 days after admission. Visual acuity in his right eye was 20/200 and his left eye had light perception alone. Both eyes showed panretinal arteritis diagnosed as acute retinal necrosis. Panretinal photocoagulation was performed for both eyes. Progression of retinal detachment was prevented in both eyes; however, visual acuity of the left eye was totally lost because of neovascular glaucoma. Visual acuity of the right eye recovered to $20 / 20$.

Conclusion: Although cases of bilateral acute retinal necrosis have been reported after herpetic encephalitis, this condition is rare after herpetic meningitis. Prophylactic acyclovir therapy and early panretinal photocoagulation may prevent retinal detachment and improve the prognosis. Neurologists and ophthalmologists should be aware that not only herpetic encephalitis but also herpetic meningitis can lead to acute retinal necrosis within a very short interval.

Keywords: acute retinal necrosis, herpetic meningitis, herpes simplex, varicella zoster virus

\section{Introduction}

Acute retinal necrosis (ARN) was first described as a rapidly progressive unilateral necrotizing retinitis in 1971 by Urayama et al. ${ }^{1}$ ARN usually presents unilaterally and has a poor prognosis. Bilateral cases have also been reported. ${ }^{2}$ To prevent a poor outcome, ARN requires aggressive management. ${ }^{3}$ Although several case reports have described the occurrence of ARN after herpetic encephalitis, ${ }^{4-8} \mathrm{ARN}$ after herpetic meningitis is rare. ${ }^{9}$ Here, we report the case of a healthy immunocompetent man with bilateral ARN that occurred in combination with herpetic meningitis during the administration of intravenous acyclovir.

\section{Case report}

A 47-year-old man was admitted with the chief complaint of persistent high fever and transient loss of consciousness. The patient was somnolent and complained of posterior cervical pain but nuchal rigidity was unclear. A painless erythematous macule with blistering was observed on both upper eyelids and several painless erythematous macules with blisters were observed on the left side of the chest. The patient had no medical history indicative of an immunocompromised state. Cerebrospinal examination showed monocyte-dominant cell count elevation. Glucose was maintained at a normal level and cerebrospinal fluid was negative for herpes simplex 
virus (HSV) DNA and varicella zoster virus (VZV) DNA. Brain T2-weighted magnetic resonance imaging revealed no findings of herpetic encephalitis, such as hyperintensity corresponding to edematous changes in the temporal lobes (Figure 1). Therefore, viral meningitis was suspected and administration of intravenous acyclovir was initiated at $750 \mathrm{mg}$ every 8 hours $(10 \mathrm{mg} / \mathrm{kg}$ every 8 hours; the patient's body weight was $75 \mathrm{~kg}$ ).

Three days after admission, the patient's consciousness status slightly improved but binocular diplopia and blurred vision suddenly occurred. Eye position was slightly esotropic and abduction was limited. In addition, several new sharply circumscribed erythematous macules appeared on the right and left upper and lower extremities. Cerebrospinal fluid was again negative for HSV DNA.

Four days after admission, the visual acuity was 20/200 oculus dexter (OD) and light perception oculus sinister (OS). The intraocular pressures were $4 \mathrm{mmHg}$ OD and $3 \mathrm{mmHg}$ OS. The right and left corneas were clear, but flare and many cells were observed in both anterior chambers and vitreous bodies. Optic disc swelling, macular edema, exudation along blood vessels, narrowing of arterioles, dilatation of venules, and superficial retinal hemorrhages were observed in both retinas (Figure 2A). One necrotic lesion was observed in the left eye. The ophthalmoscopic findings met the diagnostic criteria ${ }^{10}$ for ARN. Oral administration of prednisolone and ocular instillation of betamethasone sodium phosphate and

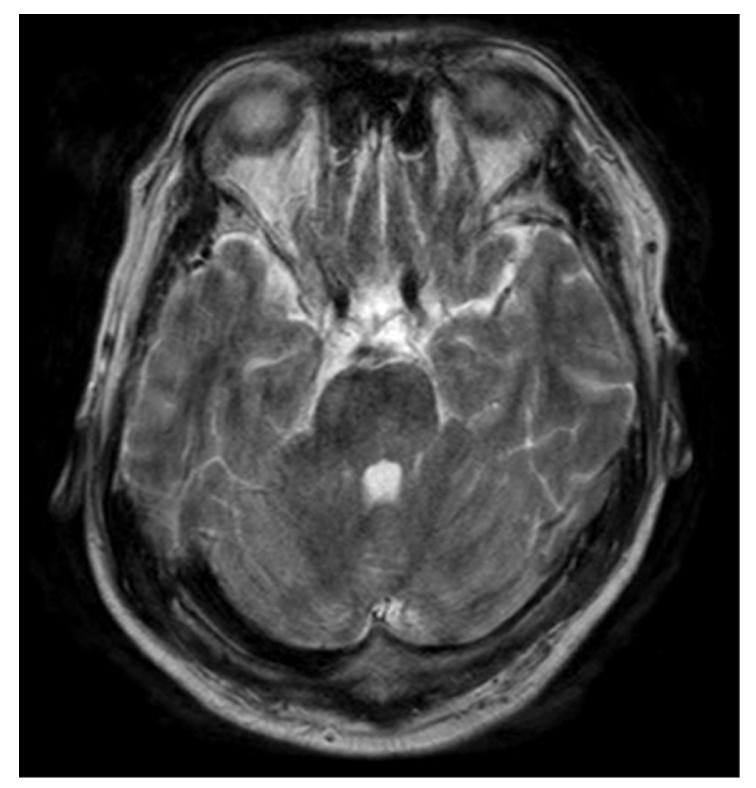

Figure I T2-weighted magnetic resonance imaging findings.

Note: No changes were observed in the signal intensity of the inferior frontal lobe and insular cortex.
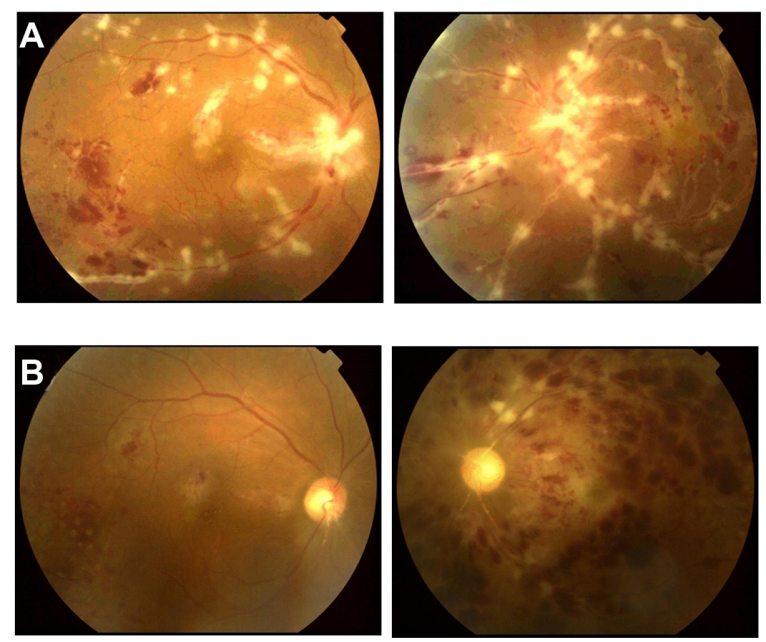

Figure 2 (A) Ophthalmoscopic findings at the time of diagnosis of ARN. Optic disc swelling, macular edema, exudation along blood vessels, narrowing of arterioles, dilatation of venules, and superficial hemorrhages were observed in both retinas. (B) Ophthalmoscopic findings 19 days after retinal photocoagulation. Optic disc swelling, macular edema, and exudation following the course of blood vessels were alleviated in both eyes. Central retinal vein occlusion was observed in the left eye, resulting in neovascular glaucoma.

tropicamide were initiated and subsequently tapered over several weeks.

Five days after admission, panretinal photocoagulation was performed for both eyes. Although the patient's body temperature had returned to normal 5 days after admission, medical treatment was continued. Inflammation, optic disc swelling, macular edema, and exudation along blood vessels were alleviated in the right eye and the visual acuity of this eye had improved to 20/20 4 months later. However, massive retinal hemorrhage derived from central vein occlusion appeared in the left eye 19 days after panretinal photocoagulation and the hemorrhage extended to vitreous 26 days after photocoagulation. All sight was lost due to neovascular glaucoma approximately 1 month after the occurrence of the hemorrhage; however, rhegmatogenous retinal detachment was prevented by photocoagulation in both eyes (Figure 2B).

By 25 days after admission, the patient's general condition and ophthalmoscopic findings had improved, and he was treated as an outpatient.

\section{Discussion}

In this patient, bilateral ARN occurred in combination with herpetic meningitis. The onset of ARN occurred a few days after the administration of intravenous acyclovir, although the patient was not immunocompromised. Both eyes were simultaneously affected with ARN. Watanabe et al ${ }^{11}$ 
reported a case in which bilateral ARN occurred after HSV type 1 meningitis. In their case, the retinal findings deteriorated and retinal detachment occurred in both eyes. In our case, we prevented rhegmatogenous retinal detachment in both eyes. This may be partly due to the administration of intravenous acyclovir before the onset of retinal symptoms as well as early panretinal photocoagulation. Serological test results were negative for VZV antibodies and the results of cerebrospinal examination were negative for HSV DNA and VZV DNA. Administration of acyclovir improved the patient's general condition, suggesting that herpes viruses were the causal agent. Ganatra et $\mathrm{al}^{12}$ reported six out of seven patients diagnosed with ARN in whom HSV type 1 DNA was detected had a history of HSV encephalitis and three out of six patients with HSV type 2 DNA had a likely history of HSV meningitis. Therefore, they concluded that herpes simplex virus is likely to be the viral cause of central nervous system infection in a patient with acute retinal necrosis syndrome. It is possible that isolated meningitis can be accidentally coincident with ARN; however, in our case, we believe this was a part of the disseminated herpetic virus infection. Vandercam et $\mathrm{al}^{13}$ reported an overall interval of 5 weeks (14 days to 2 months) between VZV encephalitis and ARN. However, as far as the authors of the present report are aware, a bilateral ARN occurring in an immunocompetent patient following VZV encephalitis has not been previously described. In this patient, ARN occurred in both eyes simultaneously and the occurrence of ARN after encephalitis was very short.

\section{Conclusion}

Our patient showed a very rapid and rare clinical course of ARN occurring immediately after herpetic meningitis. Neurologists and ophthalmologists should be aware that not only herpetic encephalitis but also herpetic meningitis can lead to ARN within a very short interval.

\section{Disclosure}

The authors report no conflicts of interest in this work.

\section{References}

1. Urayama A, Yamad N, Sasaki T, et al. Unilateral acute uveitis with retinal periretinal arteritis and detachment. Jpn J clin Ophthalmol. 1971;25:607-619.

2. Young NJ, Bird AC. Bilateral acute retinal necrosis. Br J Ophthalmol. 1978;62:581-590.

3. Palay DA, Sternberg P Jr, Davis J, et al. Decrease in the risk of bilateral acute retinal necrosis by acyclovir therapy. Am J Ophthalmol. 1991;112(3):250-255.

4. Minckler DS, McLean EB, Shaw CM, Hendrickson A. Herpes virus hominis encephalitis and retinitis. Arch Ophthalmol. 1976;94(1):89-95.

5. Johnson BL, Wisotzkey HM. Neuroretinitis associated with herpes simplex encephalitis in an adult. Am J Ophthalmol. 1977;83(4):481-489.

6. Gain $\mathrm{P}, \mathrm{Chiquet} \mathrm{C}$, Thuret $\mathrm{G}$ et al. Herpes simplex virus type 1 encephalitis associated with acute retinal necrosis syndrome in an immunocompetent patient. Acta Ophthalmol Scand. 2002;80(5):546-549.

7. Maertzdorf J, Van der Lelij A, Baarsma GS, et al. Herpes simplex virus type 1 (HSV-1)--induced retinitis following herpes simplex encephalitis: indications for brain-to-eye transmission of HSV-1. Ann Neurol. 2001;49(1):104-106.

8. Ahmadieh H, Sajjadi SH, Azarmina M, Kalani H. Association of herpetic encephalitis with acute retinal necrosis syndrome. Ann Ophthalmol. 1991;23(6):215-219.

9. Tada Y, Negoro K, Morimatsu M, Makino H, Nishida T. Findings in a patient with herpes simplex viral meningitis associated with acute retinal necrosis syndrome. AJNR Am J Neuroradiol. 2001;22(7): $1300-1302$.

10. Holland GN. Standard diagnostic criteria for the acute retinal necrosis syndrome. Executive Committee of the American Uveitis Society. Am J Ophthalmol. 1994;117(5):663-667.

11. Watanabe J, Ashida M, Funaki A, Tazawa H, Sakaue F, Ando N. A case of acute retinal necrosis syndrome caused by herpes simplex virus type 1. Nihon Ganka Gakkai Zasshi. 1989;93(1):65-71. Japanese.

12. Ganatra JB, Chandler D, Santos C, Kuppermann B, Margolis TP. Viral causes of the acute retinal necrosis syndrome. Am J Ophthalmol. 2000;129(2):166-172.

13. Vandercam T, Hintzen RQ, de Boer JH, Van der Lelij A. Herpetic encephalitis is a risk factor for acute retinal necrosis. Neurology. 2008;71(16):1268-1274.
Clinical Ophthalmology

\section{Publish your work in this journal}

Clinical Ophthalmology is an international, peer-reviewed journal covering all subspecialties within ophthalmology. Key topics include: Optometry; Visual science; Pharmacology and drug therapy in eye diseases; Basic Sciences; Primary and Secondary eye care; Patient Safety and Quality of Care Improvements. This journal is indexed on

Submit your manuscript here: http://www.dovepress.com/clinical-ophthalmology-journal

\section{Dovepress}

PubMed Central and CAS, and is the official journal of The Society of Clinical Ophthalmology (SCO). The manuscript management system is completely online and includes a very quick and fair peer-review system, which is all easy to use. Visit http://www.dovepress.com/ testimonials.php to read real quotes from published authors. 